1966-68. During this period he chaired the committee which drew up the Society's constitution. When the rules were amended in 1978 to permit the election to life membership of residents within Australia Harley was the first to be so honoured. He was for a long time interested in the search for a suitable site for a large astronomical telescope in Australia. In cooperation with interested groups from overseas and the ANU he travelled to inspect a great many sites in N.S.W. which had been chosen initially on the basis of suitability of climate. It is interesting to note that the site at Siding Spring Mountain was favourably mentioned at a meeting at Sydney Observatory in 1957 before any of the sites were visited. As a result of a promise of the N.S.W. Government, Harley was also seeking a site for a country station for Sydney Observatory which was greatly hampered by being in the very centre of a large city. Unfortunately this plan was doomed to final disappointment.

A long time member of the Royal Society of N.S.W. Harley served on its council for an extended period. He was secretary for several years and President in 1949-50. He strongly supported the New South Wales branch of the B.A.A. which meets at Sydney Observatory. He served on its committee from the time he came to the observatory and was president on two occasions.

Throughout his career he was a supporter of education in astronomy. He lectured on spherical astronomy in the Department of Applied Mathematics at Sydney University from 1959 to 1971 and to adult education courses arranged by the Workers Educational Association and the Department of Adult Education of the University. He wrote three books on general astronomy 'The Southern Sky', 'Unveiling the Universe' and 'Planets, Suns and Galaxies'.

Harley was loved and respected by a wide circle of friends both in Australia and overseas. The hospitality extended in their home by Harley and Una is remembered with pleasure by the great number of visiting colleagues who called at the Observatory when in Sydney.

He had happy relations with his staff and his guidance and inspiration led to achievements which were outstanding for an institution so small as Sydney Observatory. This is clearly shown by the letters which were received from leading astronomers in Europe and America when it was learned that the Observatory was to close. I worked with him for over thirty years and throughout that time could not have wished for a better relationship than existed between us. Even after his retirement he was still a considerable support to the Observatory and served on the Board of Visitors.

Harley will be greatly missed by us all but we can look back and be thankful for a life of great service and achievement. He was one of whom it can be truly said 'Well done thou good and faithful servant'

Bill Robertson

\section{Ron Giovanelli}

Ronald Gordon Giovanelli, DSc, FAA (1915-1984) was a foundation member of the ASA and President from 1968 to 1971. His distinguished career spanned more than forty years during which he made major contributions to science and technology. ASA members will remember him mostly for his original researches in solar optical astronomy.

The formation of the ASA was in large measure due to his foresight and energy. It is interesting to recall here his modest account of the 'birth' of the ASA as recorded in the minutes of the Inaugural Meeting of the ASA in November 1968-'Dr J. P. Wild (in the chair) after welcoming the participants called on Dr R. G. Giovanelli to outline the history of the ASA. Dr Giovanelli likened the final emergence of the Society to the build-up of a signal amidst noise. There had been rumblings over the years but it was not until early in 1966 that their amplitude exceeded that of statistical fluctuations'. The names of W. Buscombe, S. C. B. Gascoigne, R. G. Giovanelli and J. P. Wild seemed to be linked with the generation of the first signal of statistical significance.

Ron was a member of the first Council and together with Harley Wood, Paul Wild, Steve Smerd and Kevin Sheridan helped draw up the Constitution of the ASA. The Constitution Committee met regularly at the Sydney Observatory under the chairmanship of Harley Wood (then NSW Government Astronomer) to produce the draft constitution which, with small amendments, was adopted and published in the Proceedings of the ASA, Feb. 1968. After each lengthy meeting the committee adjourned to the nearby historic Hero of Waterloo hotel where further debate on the more difficult points continued. This hotel had some family significance also for Ron as it had been painted on canvas by his artist wife Katherine. Ron married in 1947 and Kath was his inseperable companion at many scientific meetings including those of the ASA.

It should be remembered that whilst Solar Astromomy was his greatest interest and to which he contributed so much nevertheless Ron was able to devote only a small part of his time to this research as his work load as Group Leader, and later Chief of the CSIRO Division of Physics was most demanding.

Ron Giovanelli began his research in solar physics as a Research Fellow at the Commonwealth Solar Observatory (now Mount Stromlo Observatory) in 1937. When war broke out he joined CSIRO, was sent to the National Physical Laboratory in England where he specialised in optics, light and photometry and on his return to Australia set up a light and optics section at the National Standards Laboratory in Sydney and made significant contributions to the war effort.

After the war he established a group for observational and theoretical studies of the Sun. He soon formed an alliance with solar radio astronomers from the nearby Division of Radiophysics, a relationship which endured until his death in 1984 and from which a number of solar optical-radio investigations resulted. He set up modern solar optical 
observatories at Fleurs and Culgoora and encouraged the development of new instruments and observing techniques.

Among Ron's many contributions on the solar atmosphere (about 100 publications) he is credited with originating the concept of magnetic field reconnection, a powerful principle underlying modern flare theory.

He helped train solar astronomers who now occupy important research positions in Australia and overseas (including J. M. Beckers, R. J. Bray, L. E. Cram, D. G. Hall, J. T. Jeffries, R. E. Loughhead, Marie McCabe and P. R. Wilson) and served in an administrative capacity on various scientific bodies (Australian National Committies on the International Geophysical Year, the International Year of the Quiet Sun, and Solar Terrestrial Physics; National Committee for Astronomy, for Space Research and for International Relations; IAU Commission 12 On Solar Radiation).

Dr Giovanelli was elected a Fellow of the Australian Academy of Science in 1962. Following his retirement in 1974 he continued his work on the Sun and completed a book 'Secrets of the Sun' (he was very happy to see the proofs which arrived two days before his death).

Commemorative functions by Australian and overseas scientists paid tribute to Ron's work - 'The R. G. Giovanelli Commemorative Colloquium' was held in Sydney (November 1984) and in Tucson, Arizona in January 1985.

For a comprehensive review of his life and work please refer to the 'Biographical Memoir, Ronald Gordon Giovanelli 1915-1984", by J. H. Piddington (Rec. Aust. Acad. Sci 6 (2) press 1985 ) from which the following paragraph is particularly appropriate.

'Giovanelli was so widely liked and admired that at his Commemorative Colloquium the President of the International Astronomical Union observed that "Ron Giovanelli helped build an International community of solar physicists because he was an enthusiastic worker and people liked him". This was true for most of the solar physicists in Europe, U.S.A., India and Japan, many of whom were personal friends and on a basis of family visits.'

\section{K. V. Sheridan}

\section{Alec Little}

\section{A tribute by B. Y. Mills}

Alec Little died suddenly of a heart attack on March 20, 1985, aged 60. He had been working at the Molonglo Radio Observatory to the end. As President of the Astronomical Society of Australia, Director of the Molonglo Radio Observatory and consultant to the CSIRO Division of Radiophysics for the Australia Telescope project, Alec was deeply involved in the Australian astronomical scene and had played a major role in many developments. His cheerful enthusiasm, forthright personality and lack of any pretensions endeared him to all his colleagues and he will be missed for these personal qualities as much as for his unequalled skills as an instrumentalist devoted to the cause of astronomy.

Alec's career was an unusual one and perhaps possible only in that bygone era when, for a gifted individual, lack of formal qualifications was no bar to advancement in a scientific career. He was born and raised in Ashfield, a suburb of Sydney, and left school in 1940, at the age of fifteen. He immediately obtained a position as a messenger and later Junior Laboratory Assistant in the Division of Radiophysics of the then CSIR (later to become CSIRO). His subsequent progress makes an inspiring success story.

I first met Alec some two years later when he was still very much a junior technician, but one whose abilities were rapidly being recognised. In those war-time days, when the Division of Radiophysics was responsible for the Australian radar effort, a keen and gifted technician was much in demand and, by the end of the war, he was generally regarded as a young man who was going places. Thus Alec was a natural choice as one of the technicians when the Division branched out into a completely new field in 1945 to establish a 'valve laboratory' as a basis for post-war research activities involving vacuum techniques. My first brief professional association with Alec came at this time when he was responsible for the successful development of a high current pulsed electron gun required for my experiments with a resonant cavity $\mathrm{X}$-ray tube-a far cry from astronomy for both of us!

The valve laboratory was abandoned as an unpromising research activity in 1947 and shortly thereafter Alec transferred to the much more promising radio astronomy group under the leadership of Joe Pawsey. This was just the kind of innovative and challenging work at which he excelled. By the time I also joined the group nearly a year later, he was already taking responsibility for the technical development of a new type of 'swept-lobe' interferometer intended for the instantaneous location of solar radio bursts; this was a project in collaboration with Ruby Payne-Scott. The interferometer was an outstanding success and produced the first direct evidence that the emitting regions were located above the photosphere and that some moved rapidly outwards. Indeed the instrument may be regarded as the precurser of the Culgoora radioheliograph. Thereafter Alec was much in demand for getting way-out projects off the ground and when I proposed the construction of a 'Cross' radio telescope in 1952, Joe Pawsey immediately assigned Alec to the project.

This was our first major association and one which really brought home to me Alec's exceptional abilities as an instrumentalist. The project naturally involved a great deal of interactive design and development but two key advances which permitted effective astronomy were due entirely to Alec-the development of simple and accurate test equipment for rapidly checking the electrical adjustment of individual dipoles and the invention of a very effective system for making absolute flux density measurements. The resulting flux density scale, unlike others of the times, has survived unchanged. 